\title{
Limiting factors in peak oxygen uptake and the relationship with functional ambulation in ambulating children with Spina Bifida
}

\author{
J. F. De Groot - T. Takken - M. A. G. C. Schoenmakers • \\ L. Vanhees · P. J. M. Helders
}

Accepted: 27 June 2008/Published online: 10 July 2008

(C) The Author(s) 2008

\begin{abstract}
The objective of this study is to interpret the outcomes of peak oxygen uptake $\left(V \mathrm{O}_{2 \text { peak }}\right)$ in children with $\mathrm{SB}$ and explore the relationship between $V \mathrm{O}_{2 \text { peak }}$ and functional ambulation using retrospective cross-sectional study. Twenty-three ambulating children with SB participated at Wilhelmina's Children's Hospital Utrecht, the Netherlands. $V \mathrm{O}_{2 \text { peak }}$ was measured during a graded treadmill-test. Eschenbacher's and Maninna's algorithm was used to determine limiting factors in reaching low $V \mathrm{O}_{2 \text { peak }}$ values. Energy expenditure during locomotion (both $\mathrm{O}_{2}$ rate and $\mathrm{O}_{2}$ cost) and percentage of $V \mathrm{O}_{2 \text { peak }}$ and $\mathrm{HR}_{\text {peak }}$ were determined during a 6-min walking test (6MWT). Differences between community and normal ambulators were analyzed. $V \mathrm{O}_{2 \text { peak }}, V \mathrm{O}_{2 \text { peak }} / \mathrm{kg}, \mathrm{HR}_{\text {peak }}$, $\mathrm{RER}_{\text {peak }}$ and $V E_{\text {peak }}$ were significantly lower compared to reference values, with significant differences between normal and community ambulators. Limiting factors
\end{abstract}

\section{J. F. De Groot · L. Vanhees}

Research Group Lifestyle and Health, University of Applied

Sciences, Utrecht, The Netherlands

J. F. De Groot - T. Takken - M. A. G. C. Schoenmakers ·

P. J. M. Helders

Department of Pediatric Physical Therapy and Exercise

Physiology, University Medical Center Utrecht, Utrecht,

The Netherlands

\section{Vanhees}

Department of Rehabilitation Sciences,

Catholic University Leuven, Louvain, Belgium

\section{J. F. De Groot ( $\square)$}

Department of Pediatric Physiotherapy and Exercise Physiology, Wilhelmina Children's Hospital, University Medical Center

Utrecht, Room kb.02.056.0., P.O. Box 85090, 3508 AB Utrecht,

The Netherlands

e-mail: J.F.degroot-16@umcutrecht.nl according to the algorithm were mostly "muscular and/or deconditioning" (47\%) and ventilatory "gasexchange" (35\%). Distance walked during 6MWT was $48.5 \%$ of predicted distance. Both $\mathrm{O}_{2}$ rate and $\mathrm{O}_{2}$ cost were high with significant differences between normal and community ambulators [17.6 vs. $21.9 \mathrm{ml} /(\mathrm{kg} \mathrm{min})$ and $0.27 \mathrm{vs} 0.43 \mathrm{ml} /$ $(\mathrm{kg} \mathrm{m})]$. Also $\% \mathrm{HR}_{\text {peak }}$ and $\% \mathrm{VO}_{2 \text { peak }}$ were significantly higher in community ambulators when compared to normal ambulators (resp. 97.6 vs. $75 \%$ and 90.2 vs. $55.9 \%$ ). $\mathrm{VO}_{\text {2peak }}$ seems to be mostly limited by deconditioning and/ or muscular components and possible ventilatory factors. For both peak values and functional ambulation, community ambulators were significantly more impaired than normal ambulators. High energy expenditure, $\% V \mathrm{O}_{2 \text { peak }}$ and $\% \mathrm{HR}_{\text {peak }}$ reflect high level of strain during ambulation in the community ambulators. Future exercise testing in children with SB should include assessment of ventilatory reserve. Exercise training in ambulatory children should focus on increasing both $V_{2} \mathrm{O}_{2 \text { peak }}$ and muscular endurance, as well as decreasing energy cost of locomotion.

Keywords Exercise test - Energy cost of locomotion . Spina Bifida $\cdot 6$ min walking test $\cdot V \mathrm{O}_{2 \text { peak }}$

\section{Introduction}

Spina bifida (SB) is the most frequently seen congenital deformity of the neural tube, with an incidence ranging from 1.4 to 3.6 of every 1,000 in the Netherlands (RIVM 2006). The severity of these deficits is largely determined by both the type and level of lesion of the SB. In $80 \%$ of children with the more serious open type of SB (Spina Bifida Aperta), hydrocephalus and a Chiari II malformation—a malformation in the brainstem—are present (Hunt 
and Poulton 1995). The level of lesion, classified according to the ASIA guidelines (Maynard et al. 1997) determines which muscles are being (partly) innervated. Besides this medical classification, children are functionally classified using the Hoffer classification (Hoffer et al. 1973), recently adapted by Schoenmakers et al. (2005), presented in Table 1 . About $20 \%$ of the lesions occur at the sacral level, enabling them to be, in most cases, community or normal ambulators. Despite high levels of functioning, these patients still experience difficulties in performing both dynamic motor skills and activities of daily living (Schoenmakers et al. 2004). This could be an important factor in inducing a cycle of less ability resulting in less activity, further reducing physical fitness and ambulation. In adolescence a large number of children seem to become wheelchair dependent as ambulation becomes too strenuous (Findley et al. 1987). Studies indeed have shown children and young adults with SB to be less active with reduced levels of physical fitness compared to their healthy peers (Agre et al. 1987; Steele et al. 1996; van den BergEmons et al. 2003a, b). Based on these results, van den Berg-Emons et al. (2003a, b) concluded that programs aimed at regular physical exercise and daily physical activity should be started in childhood to prevent further decline in physical fitness and daily functioning.

At the same time, small studies have shown higher levels of energy expenditure during ambulation in patients with SB, a finding that is associated with a pathological gait pattern (Bare et al. 2001; Buffart et al. 2006; Waters and Mulroy 1999). Energy expenditure refers to both $\mathrm{O}_{2}$ rate $\left[\mathrm{ml} \mathrm{O}_{2} /(\mathrm{kg} \mathrm{min})\right]$, an indicator of strain or effort and $\mathrm{O}_{2}$ cost $[\mathrm{ml} \mathrm{O} /(\mathrm{kg} \mathrm{m})]$ (Schwartz 2007). Higher energy expenditure during ambulation may result in higher levels of fatigue while physically active. This combination of reduced exercise capacity and higher cost of locomotion is

Table 1 Ambulation level by Hoffer et al. adapted by Schoenmakers et al. (2005)

\begin{tabular}{lc}
\hline Level of ambulation & Description \\
\hline Normal ambulation & $\begin{array}{c}\text { Independent and unrestricted } \\
\text { ambulation without use of } \\
\text { assisted devices }\end{array}$ \\
Community ambulation & Independent outdoor ambulation \\
& with or without use of braces \\
and/or assisted devices; using \\
wheelchair for longer distances \\
Household ambulation & Using braces or assisted devices \\
for indoor ambulation; using \\
wheelchair for outdoor \\
locomotion \\
Non-functional ambulation & Walking only in therapeutic \\
Non-ambulation & situations \\
\hline
\end{tabular}

referred to as "diminished physiological fitness reserve" (McArdle et al. 1996).

In our SB clinic, 23 ambulatory children with SB were seen for sports and lifestyle advice. Results showed low levels of overall muscle strength, exercise capacity and daily physical activity (Schoenmakers et al. 2008). While designing an exercise program specifically aimed at improving both endurance and ambulation in ambulatory children with SB, the following questions were raised:

1. Which factors (cardiovascular, pulmonary or muscular) are limiting $V \mathrm{O}_{2 \text { peak }}$ in ambulatory children with SB?

2. Since components of physical fitness are associated with efficiency of movement (Bar-Or 1996), is $V O_{2 \text { peak }}$ related to oxygen expenditure during ambulation in children with SB?

\section{Methods}

Subjects

The study group consisted of a 23 ambulatory children with SB visiting the SB clinic of the University Children's Hospital in Utrecht (The Netherlands) for lifestyle and sports advice in 2004. Study procedures were approved by the University Medical Ethics Committee.

Children were included when they were (1) at least community ambulatory (see Table 1), (2) able to follow instructions regarding testing and (3) between 6 and 18 years of age. Parents and children signed informed consent prior to testing.

Exclusion criteria were medical events that might interfere with the outcomes of the testing and medical status that did not allow maximum exercise testing.

Study design

Retrospective cross-sectional study, using outcomes of incremental exercise testing and the 6-min walking test (6MWT).

\section{Demographics}

Data concerning medical history were obtained from medical records. These data included type of SB, level of lesion, use of orthotics, ambulation level, age and sex.

Body mass index (BMI)

BMI was calculated as weight $(\mathrm{kg}) /$ length $(\mathrm{m})^{2}$. This index has proven to be a reliable and valid tool to estimate 
children's nutritional status, e.g. whether they are over- or underweight (Dietz and Robinson 1998; Mei et al. 2002). Weight was measured using an electronic scale. Height was measured while standing using a wall-mounted centimeter.

Peak oxygen uptake $\left(\mathrm{VO}_{2 \text { peak }}\right)$

In exercise testing, $\mathrm{VO}_{2}$ peak is considered to be the single best indicator of aerobic exercise capacity, which is often referred to as aerobic fitness. Gas exchange analysis during an incremental ergometry test to the point of volitional termination due to exhaustion is considered the gold standard to measure $V_{2} O_{2 \text { peak }}$ (Shephard et al. 1968). Earlier studies employing exercise testing in healthy children show it is possible to test $V \mathrm{O}_{2 \text { peak }}$ in healthy children (Armstrong et al. 1996; Eiberg et al. 2005; Gulmans et al. 1997; Reybrouck et al. 1992; Rowland 1993). In this study, $V \mathrm{O}_{2 \text { peak }}$ was measured using a treadmill test (EnMill, Enraf, Delft, The Netherlands), since all children would be able to perform this test and reference values are available for both young children and adolescents. In previous studies, treadmill protocols have been used to test $V \mathrm{O}_{2 \text { peak }}$ in children with disability (Hoofwijk et al. 1995; Verschuren et al. 2006), including children with Spina Bifida (Agre et al. 1987; Shermans et al. 1997). In order to accommodate children with different ambulatory abilities, two progressive exercise test protocols were used. Children considered community ambulators were tested with a starting speed of $2 \mathrm{~km} / \mathrm{h}$, which was gradually increased by $0.25 \mathrm{~km} / \mathrm{h}$ every minute. Children classified as normal ambulators were started at a speed of $3 \mathrm{~km} / \mathrm{h}$, with the speed being increased 0.50 $\mathrm{km} / \mathrm{h}$ every minute. The protocols were continued until the patient stopped due to exhaustion, despite verbal encouragement of the test leader. During the incremental exercise test, physiologic responses were measured using a heart rate (HR) monitor (Polar) and calibrated mobile gas analysis system (Cortex Metamax $\mathrm{B}^{3}$, Cortex Medical $\mathrm{GmbH}$, Leipzig, Germany). The Cortex Metamax is a valid and reliable system for measuring gas-exchange parameters during exercise (Brehm et al. 2004; Medbo et al. 2002).

Functional ambulation

Functional ambulation was measured during a 6-min walking test (6MWT). The test was performed on an 8-m track in a straight corridor and gas exchange parameters were measured continuously with a portable Cortex gas analysis system (Cortex Metamax $\mathrm{B}^{3}$, Cortex Medical $\mathrm{GmbH}$, Leipzig, Germany). Patients were instructed to cover the largest possible distance in $6 \mathrm{~min}$ at a self- selected walking speed. The test and encouragements during the test were performed in accordance with the ATS guidelines (ATS 2002).

\section{Data analysis}

Peak oxygen uptake

Peak exercise parameters were calculated as the average value over the last $30 \mathrm{~s}$ during the exercise test. Normalized $V \mathrm{O}_{2 \text { peak }}$ was calculated as $V \mathrm{O}_{2 \text { peak }} / \mathrm{kg}$. Predicted peak values were obtained from established values from age- and sex- matched historical Dutch controls (Binkhorst et al. 1991). For comparison with healthy children $Z$-scores were calculated for $V \mathrm{O}_{2 \text { peak }}, V \mathrm{O}_{2 \text { peak }} / \mathrm{kg}, \mathrm{HR}_{\text {peak }} \mathrm{RER}_{\text {peak }}$ and $V E_{\text {peak. }}$. Standard deviation scores $>2$ SD below or above normal were considered to be significantly different from the norm values.

Data were evaluated using the algorithm from Eschenbacher and Maninna (Eschenbacher and Mannina 1990). This algorithm has been developed for the interpretation of outcomes of exercise testing in adults. For this purpose it uses cut-off points routinely measured during exercise testing in order to make a distinction between cardiac, pulmonary or "other" limitations (deconditioning and/or musculoskeletal factors) to explain exercise capacity. The following parameters were measured and used in the algorithm: $V \mathrm{O}_{2 \text { peak }}, V \mathrm{CO}_{2 \text { peak }}, V E_{\text {peak }}, V E_{\text {peak }} / V \mathrm{CO}_{2-}$ peak, anaerobic threshold (AT) and heart rate response (HRR) expressed as $\left(\mathrm{HR}_{\text {peak }}-\mathrm{HR}_{\text {rest }}\right) /\left(V \mathrm{O}_{2 \text { peak }}-V \mathrm{O}_{2 \text { rest }}\right)$. Whereas the original algorithm uses adult cut-off points, in this study values were adapted to the pediatric population, based on earlier work from our laboratory regarding maximum exercise testing parameters in healthy children (van Leeuwen et al. 2004).

In this algorithm, $V E_{\text {peak }} / V \mathrm{CO}_{2 \text { peak }}$ is a general indicator of the efficiency of the both the lungs and gas exchange; high values $\left(V E_{\text {peak }} / V C \mathrm{O}_{2 \text { peak }}>36\right)$ suggest gas exchange difficulties. Since $\mathrm{FEV}_{1}$ was not measured and no known pulmonary problems were present, it was assumed that ventilatory reserve in all children was normal. HRR refers to the increase in $\mathrm{HR}$ in relation to the increase in $V \mathrm{O}_{2}$. An excessive increase in $\mathrm{HR}(>[-6.25 \times$ age $]+150)$ might reflect either cardiac disease or deconditioning. In our patients no known cardiac history was present and therefore increased HRR was considered an indicator of deconditioning rather than cardiac disease. AT occurring at less than $40 \% \mathrm{VO}_{2 \text { peak }}$ was considered an indicator of poor circulatory or "pump" limitation. When no ventilatory or cardiac limitations were present, patients were considered to be limited by "other limitations". 


\section{Functional ambulation}

The following functional parameters were measured based on the 6MWT: (1) 6-min walking distance (6MWD) and percentage of predicted 6MWD. Predicted 6MWD was calculated using the formula of Li et al. (2007), based on heart rate increase and sex (see Eqs. 1 and 2);(2) $\mathrm{O}_{2}$ rate as uptake per minute $[\mathrm{ml} /(\mathrm{kg} \mathrm{min})]$;

$$
\begin{aligned}
& 554.16+\left(\left(\mathrm{HR}_{6 \mathrm{~min}}-\mathrm{HR}_{\text {rest }}\right) \times 1.76\right) \\
& +(\text { height }(\mathrm{cm}) \times 1.23) \text { Boys } \\
& 526.79+\left(\left(\mathrm{HR}_{6 \text { min }}-\mathrm{HR}_{\text {rest }}\right) \times 1.66\right) \\
& +(\text { height }(\mathrm{cm}) \times 0.62) \text { Girls }
\end{aligned}
$$

Steady state was taken as the average value over the period during which oxygen uptake changed less than $5 \%$ (Schwartz 2007); (3) Subsequently, the following parameters were derived: Speed $(\mathrm{m} / \mathrm{min})$, calculated as $6 \mathrm{MWD} / 6 ; \mathrm{O}_{2}$ cost $[\mathrm{ml} /(\mathrm{kg} \mathrm{m})]$, calculated as $\mathrm{O}_{2}$ rate/ speed (Waters and Mulroy 1999); individual strain $\left(\mathrm{O}_{2}\right.$ rate $_{\text {steady state }} / V \mathrm{O}_{2 \text { peak }} \times 100 \%$ and maximum $\mathrm{HR}_{6 \mathrm{mwt}} /$ $\left.\mathrm{HR}_{\text {peak }} \times 100 \%\right)$

For all measurements, $t$ tests were used to test differences between normal and community ambulators after testing for normal distribution and equality of means. When this was not the case $\left(V \mathrm{O}_{2 \text { peak }}\right)$, Mann-Whitney $U$ test were used. For the correlation between $V \mathrm{O}_{2 \text { peak }}$ and $\mathrm{O}_{2}$ expenditure, a Spearman Rho was calculated. Significance level was set at $p<0.05$. Statistical analyses were performed using SPSS for Windows (version 15.0, SPSS Inc, Chicago, Ill.).

\section{Results}

Population

The study population consisted of 23 children (13 boys/11 girls, age 6-17) with either SB aperta $(n=16)$ or SB occulta $(n=7)$. Children's age, height, weight and BMI are described in Table 2. The level of lesion, classified according to the ASIA guidelines (Maynard et al. 1997) and the ambulation level are presented in Table 3 .

Peak oxygen uptake and other peak parameters

Out of 23 children, 21 performed the treadmill test without any significant problems. Two did not participate due to anxiety $(n=1)$ or pain during ambulation $(n=1) . V \mathrm{O}_{2 \text { peak }}$, $V \mathrm{O}_{2 \text { peak }} / \mathrm{kg}, \mathrm{HR}_{\text {peak }}, V E_{\text {peak }}, V \mathrm{CO}_{2 \text { peak }}$ and $\mathrm{RER}_{\text {peak }}$ and their $Z$ scores are presented in Table 4 .

One tailed $t$ test showed a significant difference between the normal and community ambulators for $Z$ scores of
Table 2 Subjects characteristics

\begin{tabular}{lcl}
\hline & Mean (SD) & $\begin{array}{l}Z \text { scores }(\mathrm{SD}) \text { compared } \\
\text { to reference values }\end{array}$ \\
\hline Age (years) & $10.4(3.1)$ & \\
Height $(\mathrm{m})$ & $1.4(0.18)$ & -0.09 \\
Weight $(\mathrm{kg})$ & $37.5(12.7)$ & 0.4 \\
BMI $\left(\mathrm{kg} / \mathrm{m}^{2}\right)$ & $18.4(2.9)$ & 1.4 \\
\hline
\end{tabular}

Table 3 Level of lesion and functional ambulation level

\begin{tabular}{lc}
\hline & Number $(\%)$ \\
\hline Level of lesion & \\
L5-S1 & $10(43.5)$ \\
S1-S4 & $6(26.1)$ \\
No motor loss & $7(30.4)$ \\
Ambulation level & \\
Normal ambulator & $17(74)$ \\
Community ambulator & $6(26)$ \\
Use of orthotics & $13(56)$ \\
\hline
\end{tabular}

$V \mathrm{O}_{2 \text { peak }}, V \mathrm{O}_{2 \text { peak }} / \mathrm{kg}, \mathrm{HR}_{\text {peak }}, V E_{\text {peak }}$ scores and outcomes of $V \mathrm{CO}_{2 \text { peak }}$ and $V \mathrm{O}_{2 \text { peak }} / \mathrm{kg}$. Normal ambulators showed higher scores for both ventilation, $V \mathrm{O}_{2 \text { peak }}$ and $V \mathrm{CO}_{2 \text { peak }}$. Ventilatory equivalents for both carbon dioxide and oxygen $\left(V E_{\text {peak }} / V C \mathrm{O}_{2 \text { peak }}\right.$ and $\left.V E_{\text {peak }} / V \mathrm{O}_{2 \text { peak }}\right)$ did not differ, but were high in both groups.

Limiting factors using Eschenbacher's and Mannina's algorithm

Eighty-five percent of complete test data $(n=20)$ scored below $90 \%$ of predicted $\mathrm{VO}_{2 \text { peak }}$, indicating lower levels of fitness than expected.

Looking at the limiting factors, $47 \%$ showed signs of "other limitation", e.g. muscular deficiency and/or deconditioning, as indicated by high heart rate response (HRR).

Thirty-five percent showed possible signs of insufficient gas exchange at the pulmonary level, as indicated by $V E_{\text {peak }} / V \mathrm{CO}_{2 \text { peak }}>36$ Table 5 .

Functional ambulation

Ambulation parameters from 22 children were analyzed. Results are shown in Table 6 and Figs. 1 and 2. A steady state was reached in 20 children after the 2 or $3 \mathrm{~min}$ of walking in both groups. A difference between normal and community ambulators is clear throughout the 6MWT, with significant differences starting during minute 2 . 
Table 4 Descriptives of exercise testing in 21 children with SB

\begin{tabular}{lcccccc}
\hline & Mean $(\mathrm{SD})$ all children & $Z$ score $(\mathrm{SD})$ & Mean $(\mathrm{SD}) \mathrm{NA}$ & $Z$ scores $(\mathrm{SD})$ & Mean $(\mathrm{SD}) \mathrm{CA}$ & $Z$ scores $(\mathrm{SD})$ \\
\hline$V \mathrm{O}_{2 \text { peak }}(\mathrm{l} / \mathrm{min})$ & $1.28(0.57)$ & $-2.2^{\mathrm{a}}$ & $1.39(0.58)$ & -1.9 & $0.85(0.24)$ & $-3.6^{\mathrm{a}, *}$ \\
$V \mathrm{O}_{2 \text { peak }} / \mathrm{kg}[\mathrm{ml} /(\mathrm{kg} \mathrm{min})]$ & 33.14 & $-2.9^{\mathrm{a}}$ & 34.77 & $-2.5^{\mathrm{a}}$ & $26.2^{*}$ & $-4.5^{\mathrm{a}, *}$ \\
$\mathrm{HR}_{\text {peak }}(\mathrm{beats} / \mathrm{min})$ & $172.2(21.2)$ & $-3.4^{\mathrm{a}}$ & $175.5(20.8)$ & $-3.0^{\mathrm{a}}$ & $158.5(19.1)$ & $-5.0^{\mathrm{a}, *}$ \\
$V^{\prime} \mathrm{E}_{\text {peak }}(1 / \mathrm{min})$ & $45.6(19.1)$ & $-2.4^{\mathrm{a}}$ & $49.3(19.3)^{*}$ & -2.0 & $30.0(7.0)$ & $-3.8^{\mathrm{a}, *}$ \\
$V \mathrm{CO}_{2 \text { peak }}(1 / \mathrm{min})$ & $1.30(0.63)$ & $\mathrm{NA}$ & $1.42(0.65)$ & $\mathrm{NA}$ & $0.82(0.24)^{*}$ & $\mathrm{NA}$ \\
$\mathrm{RER}_{\text {peak }}\left(V \mathrm{CO}_{2} / \mathrm{VO}_{2}\right)$ & $1.00(0.13)$ & $-2.1^{\mathrm{a}}$ & $1.01(0.14)$ & -2.0 & $0.97(0.2)$ & $-2.4^{\mathrm{a}}$ \\
\hline
\end{tabular}

All $Z$ scores are in SD compared to reference values

$N A$ normal ambulator, $C A$ community ambulator

$* p<0.05$ between normal and community ambulators

${ }^{\text {a }} Z$ scores $>-2 \mathrm{SD}$

Table 5 Cut-off points in the algorithm by Eschenbacher and Maninna as measured in 21 children with SB

\begin{tabular}{llllll}
\hline & Mean & Range & Used cut off points & Indicative for & \% reaching critical values \\
\hline$V \mathrm{O}_{2 \text { peak }}$ pred (\%) & 79.6 & $51-120$ & $<90 \%$ & Low $V \mathrm{O}_{2 \text { peak }}$ & $(85 \%)$ \\
$V E / V \mathrm{CO}_{2 \text { peak }}$ & 36.6 & $27.6-52.7$ & $>36$ & Ventilatory limitations & $(35 \%)$ \\
$\mathrm{HRR}$ & 88.5 & $-0.33-182.7$ & $>(-6.25 \times$ age $)+150$ & Deconditioning and/or muscular limitations & $(47 \%)$ \\
$\mathrm{AT} \%$ & 72.3 & $35.8-98.86$ & $<44$ & Cardiovascular limitations & $(6 \%)$ \\
\hline
\end{tabular}

$V E / V \mathrm{CO}_{2}, \mathrm{HRR}$ and $\mathrm{AT} \%$ are being shown for those $V \mathrm{O}_{2 \text { peak }}$ pred $<90 \%(n=18)$

$H R R$ heart rate reserve, $A T$ anaerobic threshold

Table 6 Outcomes of $6 \mathrm{MWT}$

$* p<0.05$ between normal and community ambulators

${ }^{\text {a }}$ measured during steady state

\begin{tabular}{lccc}
\hline & $\begin{array}{l}\text { Mean }(\mathrm{SD}) \text { all } \\
\text { children }\end{array}$ & $\begin{array}{l}\text { Mean }(\mathrm{SD}) \text { normal } \\
\text { ambulators }\end{array}$ & $\begin{array}{l}\text { Mean (SD) community } \\
\text { ambulators }\end{array}$ \\
\hline 6MWD $(\mathrm{m})$ & $391.4(61)$ & $408.5(57.2)$ & $333.4(30.6)^{*}$ \\
Predicted distance $(\%)$ & $48.5(8.3)$ & $50.2(8.3)$ & $41.1(2.7)^{*}$ \\
$\mathrm{Mean}_{2}$ rate $[\mathrm{ml} /(\mathrm{kg} \mathrm{min})]$ & $18.5(3.9)$ & $17.6(3.3)$ & $21.9(4.8)^{*}$ \\
$\mathrm{O}_{2}$ rate steady state $[(\mathrm{ml} /(\mathrm{kg} \mathrm{min})]$ & $20.0(3.9)$ & $19.3(3.5)$ & $22.9(4.3)$ \\
$\mathrm{HR}_{\text {max6MwT }}$ & $134(18)$ & $129(15)$ & $150(14)^{*}$ \\
$\mathrm{O}_{2}$ cost $[(\mathrm{ml} /(\mathrm{kg} \mathrm{m})]$ & $0.3(0.09)$ & $0.27(0.06)$ & $0.43(0.07)^{*}$ \\
$\% \mathrm{VO}_{2 \text { peak }}{ }^{2}$ & $63.1(20)$ & $55.9(14.3)$ & $90.2(7.6)^{*}$ \\
$\% \mathrm{HR}_{\text {peak }}$ & $80(14.8)$ & $75(11.6)$ & $97.6(11.6)^{*}$ \\
$\mathrm{Speed}(\mathrm{km} / \mathrm{h})$ & $3.9(0.6)$ & $4.1(0.6)$ & $3.3(0.3)^{*}$ \\
\hline
\end{tabular}

Average distance walked was $391.4( \pm 61) \mathrm{m}$, which was $48.5 \%$ of predicted distance. Significant differences were seen between the community and normal ambulators regarding distance $(p<0.01)$, \%predicted distance $(p<$ $0.05)$, speed $(p<0.01)$, oxygen rate $(p<0.05)$, oxygen cost $(p<0.0005)$, maximum HR reached during 6MWT ( $p$ $<0.015), \% V \mathrm{O}_{2 \text { peak }}(p<0.0001)$ and $\% \mathrm{HR}_{\text {peak }}(p<0.04)$. Figures 1 and 2 show $\mathrm{O}_{2}$ rate and $\% V \mathrm{O}_{2}$ during the 6MWT. Percentage $V \mathrm{O}_{2 \text { peak }}$ during the 6MWT averaged $63.1 \%$ $( \pm 20 \%)$, with significant differences between normal and community ambulators (55.9 vs. 90.2\%). Similar differences were seen for $\% \mathrm{HR}_{\text {peak }}$, respectively 75.0 versus $97.6 \%$ for normal versus community ambulators. Both $\mathrm{O}_{2}$ rate and $\mathrm{O}_{2}$ cost were high with significant differences between normal and community ambulators [17.6 vs. 21.9 $\mathrm{ml} /(\mathrm{kg} \mathrm{min})$ and $0.27 \mathrm{vs} .0 .43 \mathrm{ml} /(\mathrm{kg} \mathrm{m})]$. The community ambulators walked more slowly and thus covered less distance, while performing the task at a much higher percentage of their maximum capacity and at the same time requiring more energy during locomotion.

Correlation between $V \mathrm{O}_{2 \text { peak }}$ and oxygen utilization during ambulation

Both $\mathrm{O}_{2}$ rate and $\mathrm{O}_{2}$ cost during 6MWT correlated negatively with $V \mathrm{O}_{2 \text { peak }}$ (respectively $r_{\mathrm{sp}}=-0.56(p<0.001)$ 


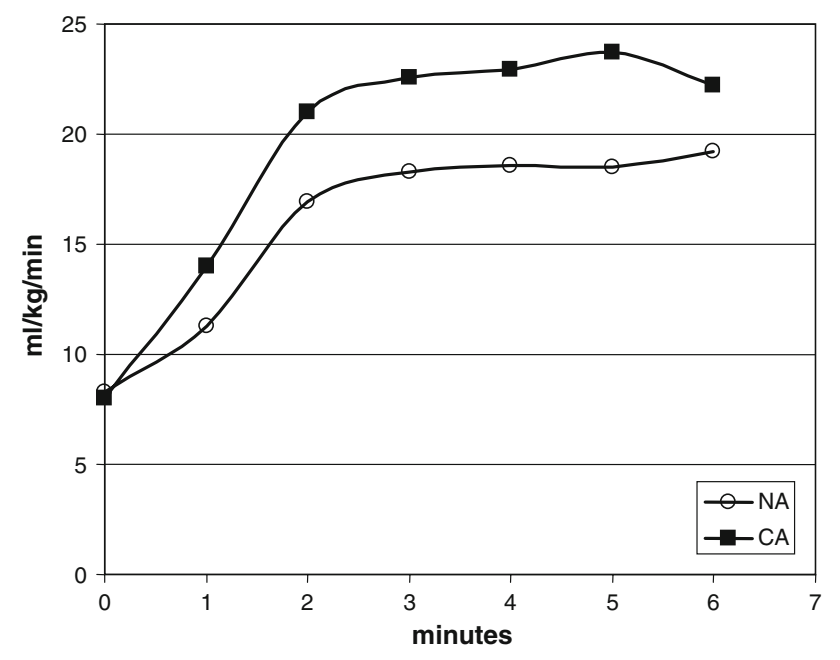

Fig. $1 \mathrm{O}_{2}$ rate during 6MWT comparing normal and community ambulators

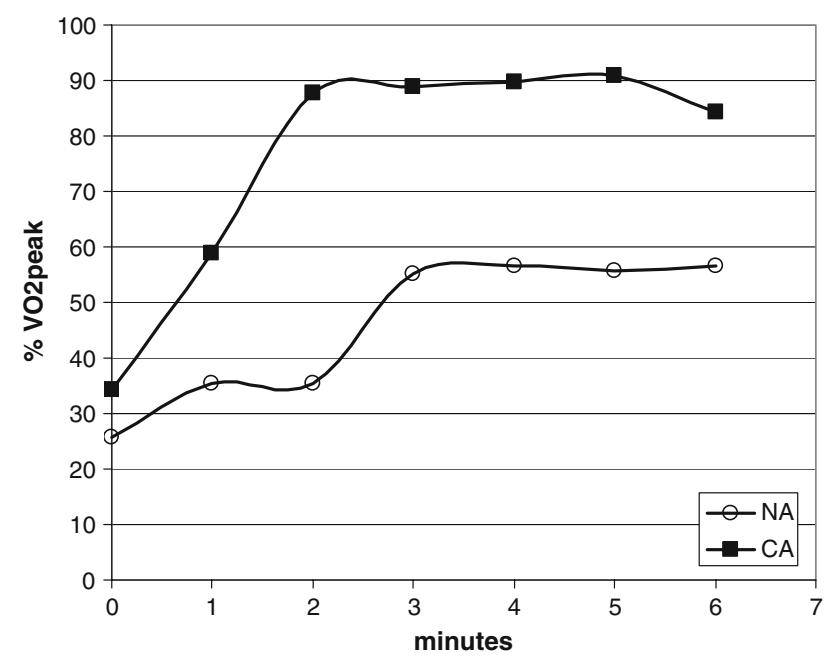

Fig. $2 \% \mathrm{VO}_{2 \text { peak }}$ during $6 \mathrm{MWT}$ comparing normal and community ambulators

and $\left.r_{\mathrm{sp}}=-0.76(p<0.001)\right)$, indicating lower energy expenditure during locomotion in children reaching higher $V \mathrm{O}_{2 \text { peak. }}$.

\section{Discussion}

Peak oxygen uptake

The first purpose of the study was to determine why ambulatory children with SB showed significantly reduced levels of $V \mathrm{O}_{2 \text { peak }}$ compared to healthy peers. Despite subjective signs of peak effort, the treadmill testing resulted in both low $\mathrm{HR}_{\text {peak }}$ and $\mathrm{RER}_{\text {peak }}$ values, calling into question the true maximal character of the testing procedures.
Currently we are using a protocol of Rossiter et al. (2006) using a supra-maximal step $(105-110 \%$ of last reached speed) to determine whether the regular protocol yields true maximum values or whether a different approach in exercise testing should be used in children with SB. At the same time the low $\mathrm{HR}_{\text {peak }}$ seems to be in line with other studies regarding exercise testing in children with SB (Agre et al. 1987; Shermans et al. 1997) with $\mathrm{HR}_{\text {peak }}$ ranging from 130 to 185 beats per minute. In one of these studies (Agre et al. 1987) $\mathrm{HR}_{\text {peak }}$ seems negatively related to level of lesion. Another explanation for low $\mathrm{HR}_{\text {peak }}$ could be that exercise capacity in children with SB is not limited by the cardiovascular system, but by muscular components.

Using the algorithm (Eschenbacher and Mannina 1990), limiting factors in exercise capacity in ambulatory children with SB indeed seem to be mostly "deconditioning and/or muscular" components. Muscular limitations can partly be explained by the disease itself. Lower muscle mass in children with SB results in lower $V \mathrm{O}_{2 \text { peak }} . V \mathrm{O}_{2 \text { peak }} / \mathrm{kg}$ was even more reduced. This is likely a result of the different body composition in these children with less active muscle mass and increased fat mass (Liusuwan et al. 2007b). In contrast with the muscular consequences of the disease, atrophy and muscular inefficiency as a result of disuse and sedentary lifestyle can be expected to improve through a training program. In the studied population, not only was exercise capacity reduced, they also showed lower strength above the lesion level and a sedentary lifestyle (Schoenmakers et al. 2008). In combination with a high HRR, the muscular limitations indentified in this study seem partly due to deconditioning. Exercise programs aimed at improving physical fitness in ambulatory children with SB are scarce, but they do show significant improvements in both strength and endurance (Andrade et al. 1991; Liusuwan et al. 2007a; Widman et al. 2006).

In this study high ventilatory equivalents were found for both $V \mathrm{CO}_{2}$ and $V \mathrm{O}_{2}$, which could be an indicator of ventilatory limitations. These findings are consistent with one other study reporting on pulmonary dysfunction due to restrictive lung disease and respiratory muscle weakness in children with SB during exercise (Shermans et al. 1997).

Another possible explanation for these high ventilatory equivalents might be the presence of a Chiari II malformation, often present in children with SB. This malformation affects the brain stem and is known to influence both $\mathrm{O}_{2}$ and $\mathrm{CO}_{2}$ peripheral chemoreceptor function in children with SB (Gozal et al. 1995; Petersen et al. 1995). Future studies should include assessment of ventilatory reserve during exercise, so that a distinction can be been made between the different causes of pulmonary limitations, e.g. diffusion type versus gas exchange versus mechanical limitations. 
Functional ambulation

Our second purpose was to determine the relationship between $V \mathrm{O}_{2 \text { peak }}$ and functional ambulation. The $6 \mathrm{MWT}$ is a submaximal test of functional exercise capacity (Li et al. 2007). One of the main outcomes is the distance walked. In our study only half of the predicted distance was reached. A likely reason for reduced 6MWD is reduced muscle strength resulting in decreased motor control and an altered gait pattern leading to high energy expenditure (Gutierrez et al. 2005; Waters and Mulroy 1999). In this study, both $\mathrm{O}_{2}$ rate and $\mathrm{O}_{2}$ cost were indeed high compared to values for healthy children, which range in the literature from 12 to 18 $\mathrm{ml} /(\mathrm{kg} \mathrm{min})$ and 0.18 to $0.27 \mathrm{ml} /(\mathrm{kg} \mathrm{m})$. In the literature values for $\mathrm{O}_{2}$ rate and $\mathrm{O}_{2}$ cost during ambulation in children with $\mathrm{SB}$ range from 17.5 to $19 \mathrm{ml} /(\mathrm{kg} \mathrm{min})$ and from 0.28 to $0.47 \mathrm{ml} /(\mathrm{kg} \mathrm{m})$ (Bartonek et al. 2002; Gutierrez et al. 2005). The $\mathrm{O}_{2}$ rate in our study was higher, while the cost ranged from $0.27 \mathrm{ml} /(\mathrm{kg} \mathrm{min})$ in normal ambulators to $0.43 \mathrm{ml} /(\mathrm{kg}$ min) in community ambulators. These other studies used different protocols regarding both mode of testing (treadmill vs. level ground), walking speed (self-selected vs. imposed) and preparation of the subjects, factors hinderomg comparison between the studies. Therefore we are using new protocols, proposed in recent literature (Brehm et al. 2007; Schwartz 2007) in our current study.

Another interesting result from this study is the individual level of strain during locomotion. Community ambulators showed a much higher HR during the 6MWT than normal ambulators. Studies in healthy children show HR reached during the 6MWT to be around 134 beats per minute, which is similar to the normal ambulators (Lammers et al. 2007; Li et al. 2005). Looking at the intensity of ambulation, community ambulators performed this task at a very high level of individual strain $\left(91 \% V_{2} \mathrm{O}_{2 \text { peak }}\right.$ and $\left.97.6 \% \mathrm{HR}_{\text {peak }}\right)$. Studies in healthy children reach $65-70 \%$ of $\mathrm{HR}_{\text {peak }}$ during the 6MWT (Paap et al. 2005). One explanation for this could be the low $\mathrm{HR}_{\text {peak }}$ reached during the exercise test. But as mentioned above the community ambulators reached a high HR during the 6MWT. In combination with high oxygen utilization, the effort of walking remains high.

\section{Correlation between $\mathrm{VO}_{2 \text { peak }}$ and oxygen utilization} during ambulation

$V \mathrm{O}_{2 \text { peak }}$ values were related to oxygen utilization during locomotion. This indicates lower levels of peak oxygen uptake are associated with both higher oxygen rate and oxygen cost during locomotion. Rate is indicator of strain or effort, which might explain the level of fatigue during locomotion. Reybrouck et al observed similar trends in treadmill testing when comparing children with chronic fatigue with healthy peers, concluding that high individual strain was associated with early fatigue (Reybrouck et al. 2007).

Energy cost is an indicator of efficiency (Schwartz 2007). From the literature it is known that energy cost of locomotion in people with disabilities can be improved by training (Felici et al. 1997; Protas et al. 2001), so future research should also look at the effects of training to reduce the energy cost during locomotion in ambulatory children with SB.

\section{Limitations of the study}

Questions could be raised with regards to use of a treadmill protocol. Other studies (Bruinings et al. 2007; van den Berg-Emons et al. 2003a, b; Widman et al. 2007) have used upper extremity ergometry. An advantage of arm ergometry in this population could be that the muscles tested are less involved in the disease process. In this way the outcomes of the test might more closely reflect cardiorespiratory limitations in exercise testing. On the other hand, upper extremity ergometry has been known to result in lower $V \mathrm{O}_{2 \text { peak }}$ values, due to the smaller muscle mass being involved in testing (Franklin 1985). In this study a treadmill protocol was chosen for several reasons. First, for all children, ambulation was the main mode of transportation. In this case it is recommended to use a treadmill for maximum exercise testing, due to the specificity of testing (Stromme et al. 1977). Secondly, we were interested in comparing outcomes from the peak exercise test to other ambulation parameters. If we had used arm ergometry, these comparisons would be hard to interpret due to the differences in physiological responses between arm ergometry and treadmill testing. In this study the 6MWT was performed using an 8-m track. Looking at the studies establishing reference values (Geiger et al. 2007; Lammers et al. 2007; Li et al. 2007) for the 6MWD in children, a $20 \mathrm{~m}$ track seems to result in a longer 6MWD. In this study however, the children were walking with a significantly lower speed as compared to healthy children reducing the importance of the shorter distance between the turning points. Despite this shorter track a steady state of $\mathrm{O}_{2}$ utilization was reached by all, but two children. Currently we are working with the more commonly used $20 \mathrm{~m}$ track.

\section{Conclusion}

Lower levels of $\mathrm{VO}_{2 \text { peak }}$ in ambulatory children with $\mathrm{SB}$ seem to be related to muscular and/or deconditioning components rather than cardiopulmonary deficiencies. Future exercise testing in ambulatory children with SB should include evaluation of the ventilatory reserve to better determine possible ventilatory limitations. 
Both $\mathrm{O}_{2}$ rate and $\mathrm{O}_{2}$ cost during locomotion are high in ambulatory children with $\mathrm{SB}$, even in those considered to be normal ambulators. Oxygen utilization correlated negatively with $V \mathrm{O}_{2 \text { peak }}$. Overall, community ambulators showed significantly worse outcomes than normal ambulators. At the same time, the normal ambulators only walked half of the predicted distance at high $\mathrm{O}_{2}$ rate and $\mathrm{O}_{2}$ cost. Future training programs for ambulatory children with SB should focus on improving $V \mathrm{O}_{2 \text { peak }}$ and muscular endurance, as well as decreasing energy expenditure during locomotion to increase physiological reserve.

Open Access This article is distributed under the terms of the Creative Commons Attribution Noncommercial License which permits any noncommercial use, distribution, and reproduction in any medium, provided the original author(s) and source are credited.

\section{References}

Agre JC, Findley TW, McNally MC, Habeck R, Leon AS, Stradel L et al (1987) Physical activity capacity in children with myelomeningocele. Arch Phys Med Rehabil 68:372-377

Andrade CK, Kramer J, Garber M, Longmuir P (1991) Changes in selfconcept, cardiovascular endurance and muscular strength of children with spina bifida aged 8 to 13 years in response to a 10week physical-activity programme: a pilot study. Child Care Health Dev 17:183-196. doi:10.1111/j.1365-2214.1991.tb00689.x

Armstrong N, Welsman J, Winsley R (1996) Is peak $V \mathrm{O}_{2}$ a maximal index of children's aerobic fitness? Int J Sports Med 17:356-359. doi: $10.1055 / \mathrm{s}-2007-972860$

ATS (2002) ATS statement: guidelines for the six-minute walking test. Am J Respir Crit Care Med 166:111-117

Bare A, Vankoski SJ, Dias L, Danduran M, Boas S (2001) Independent ambulators with high sacral myelomeningocele: the relation between walking kinematics and energy consumption. Dev Med Child Neurol 43:16-21. doi:10.1017/ S0012162201000032

Bar-Or O (1996) Role of exercise in the assessment and mannagement of neuromuscular disease in children. Med Sci Sports Exerc 28:421-427. doi:10.1097/00005768-199604000-00005

Bartonek A, Eriksson M, Saraste H (2002) Heart rate and walking velocity during independent walking in children with low and Midlumbar Myelomeningocele. Pediatr Phys Ther 14:185-190. doi:10.1097/00001577-200214040-00003

Binkhorst RA, van 't Hof MA, Saris WH (1991) Maximum inspanning door kinderen; referentiewaarden voor 6-18 jarige meisjes en jongens (Maximum exercise in children; reference values for girls and boys, 6-18 years of age), Nederlandse Hartstichting, Den Haag

Brehm MA, Harlaar J, Groepenhof H (2004) Validation of the portable VmaxST system for oxygen-uptake measurement. Gait Posture 20:67-73. doi:10.1016/S0966-6362(03)00097-3

Brehm MA, Knol DL, Harlaar J (2008) Methodological considerations for improving the reproducibility of walking efficiency outcomes in clinical gait studies. Gait Posture 27(2):196-201

Bruinings AL, van den Berg-Emons HJ, Buffart LM, van der Heijden-Maessen HC, Roebroeck ME, Stam HJ (2007) Energy cost and physical strain of daily activities in adolescents and young adults with myelomeningocele. Dev Med Child Neurol 49:672-677
Buffart LM, Roebroeck ME, van den Berg-Emons HJ, Stam HJ (2006). Determinanten van dagelijkse lichamelijke activiteit en fitheid bij adolescenten en jong volwassenen met meningocèle (Rep. No. Erasmus University)

Dietz WH, Robinson TN (1998) Use of the body mass index (BMI) as a measure of overweight in children and adolescents. J Pediatr 132:191-193. doi:10.1016/S0022-3476(98)70426-3

Eiberg S, Hasselstrom H, Gronfeldt V, Froberg K, Svensson J, Andersen LB (2005) Maximum oxygen uptake and objectively measured physical activity in Danish children 6-7 years of age: the Copenhagen school child intervention study. Br J Sports Med 39:725-730. doi:10.1136/bjsm.2004.015230

Eschenbacher WL, Mannina A (1990) An algorithm for the interpretation of cardiopulmonary exercise tests. Chest 97:263-267. doi: 10.1378/chest.97.2.263

Felici F, Bernardi M, Radio A, Marchettoni P, Castellano V, Macaluso A (1997) Rehabilitation of walking for paraplegic patients by means of a treadmill. Spinal Cord 35:383-385. doi: 10.1038/sj.sc. 3100403

Findley TW, Agre JC, Habeck RV, Schmalz R, Birkebak RR, McNally MC (1987) Ambulation in the adolescent with myelomeningocele I: early childhood predictors. Arch Phys Med Rehabil 68:518-522

Franklin BA (1985) Exercise testing, training and amr ergometry. Sports Med 2:100-119

Geiger R, Strasak A, Treml B, Gasser K, Kleinsasser A, Fischer V et al (2007) Six-minute walk test in children and adolescents. J Pediatr 150:395-399

Gozal D, Arens R, Omlin KJ, Jacobs RA, Keens TG (1995) Peripheral chemoreceptor function in children with myelomeningocele and Arnold-Chiari malformation type 2. Chest 108:425-431. doi: 10.1378/chest.108.2.425

Gulmans VA, De MK, Binkhorst RA, Helders PJ, Saris WH (1997) Reference values for maximum work capacity in relation to body composition in healthy Dutch children. Eur Respir J 10:94-97. doi:10.1183/09031936.97.10092014

Gutierrez EM, Bartonek A, Haglund-Akerlind Y, Saraste H (2005) Kinetics of compensatory gait in persons with myelomeningocele. Gait Posture 21:12-23. doi:10.1016/j.gaitpost.2003.11.002

Hoffer M, Feiwell E, Perry J, Bonnet C (1973) Functional ambulation in patients with myelomeningocele. J Bone Joint Surg Am 55:137-148

Hoofwijk M, Unnithan VB, Bar-Or O (1995) Maximal treadmill performance of children with cerebral palsy. Pediatr Exerc Sci 7:305-313

Hunt GM, Poulton A (1995) Open Spina Bifida: a complete cohort reviewed 25 years after closure. Dev Med Child Neurol 37:19-29

Lammers AE, Hislop AA, Flynn Y, Haworth SG (2007) The sixminute walk test: normal values for children of 4-11 years of age. Arch Dis Child 93:464-468

Li AM, Yin J, Yu CC, Tsang T, So HK, Wong E et al (2005) The sixminute walk test in healthy children: reliability and validity. Eur Respir J 25:1057-1060. doi:10.1183/09031936.05.00134904

Li AM, Yin J, Au JT, So HK, Tsang T, Wong E et al (2007) Standard reference for the six-minute-walk test in healthy children aged 7 to 16 years. Am J Respir Crit Care Med 176:174-180. doi: $10.1164 / \mathrm{rccm} .200607-8830 \mathrm{C}$

Liusuwan RA, Widman LM, Abresch RT, Johnson AJ, McDonald CM (2007a) Behavioral intervention, exercise, and nutrition education to improve health and fitness (BENEfit) in adolescents with mobility impairment due to spinal cord dysfunction. J Spinal Cord Med 30(Suppl 1):S119-S126

Liusuwan RA, Widman LM, Abresch RT, Styne DM, McDonald CM (2007b) Body composition and resting energy expenditure in patients aged 11 to 21 years with spinal cord dysfunction 
compared to controls: comparisons and relationships among the groups. J Spinal Cord Med 30(Suppl 1):S105-S111

Maynard FM, Bracken MB, Creasey G, Ditunno JF Jr, Donovan WH, Ducker TB et al (1997) International standards for neurological and functional classification of spinal cord injury. Am Spinal Injury Association. Spinal Cord 35:266-274. doi:10.1038/sj.sc. 3100432

McArdle WD, Katch KF, Katch VL (1996) Energy, Nutrition and Human Performance. William and Wilkins, Baltimore

Medbo JI, Mamen A, Welde B, von Heimburg E, Stokke R (2002) Examination of the Metamax I and II oxygen analysers during exercise studies in the laboratory. Scand J Clin Lab Invest 62:585-598. doi:10.1080/003655102764654321

Mei Z, Grummer-Strawn LM, Pietrobelli A, Goulding A, Goran MI, Dietz WH (2002) Validity of body mass index compared with other body-composition screening indexes for the assessment of body fatness in children and adolescents. Am J Clin Nutr 75:978-985

Paap E, van der Net J, Helders PJM, Takken T (2005) Physiologic resonse of the six-minute walk test in children with juvenile idiopathic arthritis. Arthritis Rheum 53:351-356. doi:10.1002/ art. 21175

Petersen MC, Wolraich M, Sherbondy A, Wagener J (1995) Abnormalities in control of ventilation in newborn infants with myelomeningocele. J Pediatr 126:1011-1015. doi:10.1016/ S0022-3476(95)70236-9

Protas EJ, Holmes SA, Qureshy H, Johnson A, Lee D, Sherwood AM (2001) Supported treadmill ambulation training after spinal cord injury: a pilot study. Arch Phys Med Rehabil 82:825-831. doi: 10.1053/apmr.2001.23198

Reybrouck T, Deroost F, Van der Hauwaert LG (1992) Evaluation of breath-by-breath measurement of respiratory gas exchange in pediatric exercise testing. Chest 102:147-152. doi:10.1378/ chest.102.1.147

Reybrouck T, Vangesselen S, Mertens L, Gewillig M (2007) Efficiency of oxygen cost during exercise in patients with symptoms of fatigue during physical activities. Acta Paediatr 96:1311-1314. doi:10.1111/j.1651-2227.2007.00416.x

RIVM (2006) http://www.rivm.nl/vtv/object_document/o1762n18478. html

Rossiter HB, Kowalchuk JM, Whipp BJ (2006) A test to establish maximum $\mathrm{O}_{2}$ uptake despite no plateau in the $\mathrm{O}_{2}$ uptake response to ramp incremental exercise. J Appl Physiol 100:764770. doi:10.1152/japplphysiol.00932.2005

Rowland TW (1993) Does peak $V \mathrm{O}_{2}$ reflect $V \mathrm{O}_{2}$ max in children? Evidence from supramaximal testing. Med Sci Sports Exerc 25:689-693. doi:10.1249/00005768-199306000-00007

Schoenmakers MA, Gulmans VA, Gooskens RH, Helders PJ (2004) Spina bifida at the sacral level: more than minor gait disturbances. Clin Rehabil 18:178-185. doi:10.1191/0269215504cr718oa

Schoenmakers MA, Uiterwaal CS, Gulmans VA, Gooskens RH, Helders PJ (2005) Determinants of functional independence and quality of life in children with spina bifida. Clin Rehabil 19:677685. doi:10.1191/0269215505cr865oa
Schoenmakers MAGC, De Groot JF, Gorter JW, Hilleart JLM, Helders PJM, Takken T (2008) Muscle strength, aerobic capacity and physical activity in independent ambulating children with lumbosacral spina bifida (in press)

Schwartz MH (2007) Protocol changes can improve the reliability of net oxygen cost data. Gait Posture 26:494-500. doi: 10.1016/j.gaitpost.2007.07.014

Shephard RJ, Allen C, Benade AJ, Davies CT, Di Pampero PE, Hedman R et al (1968) The maximum oxygen uptake. An international reference standard of cardiorespiratory fitness. Bull World Health Organ 38:757-764

Shermans MS, Kaplan JM, Effgen S, Campbell D, Dold F (1997) Pulmonary dysfunction and reduced exercise capacity in patients with myelomeningocele. J Pediatr 131:413-418. doi: 10.1016/S0022-3476(97)80067-4

Steele CA, Kalnins IV, Jutai JW, Stevens SE, Bortolussi JA, Biggar WD (1996) Lifestyle health behaviours of 11-16 year old youth with physical disabilities. Health Educ Res 11:173-186. doi: 10.1093/her/11.2.173

Stromme SB, Ingler F, Meen HD (1977) Assessment of maximal aerobic power in specifically trained athletes. J Appl Physiol 42:833-837

van den Berg-Emons HJ, Bussmann JB, Meyerink HJ, Roebroeck ME, Stam HJ (2003a) Body fat, fitness and level of everyday physical activity in adolescents and young adults with meningomyelocele. J Rehabil Med 35:271-275. doi:10.1080/ 16501970310012400

van den Berg-Emons HJ, Bussmann JB, Meyerink HJ, Roebroeck ME, Stam HJ (2003b) Body fat, fitness and level of everyday physical activity in adolescents and young adults with meningomyelocele. J Rehabil Med 35:271-275. doi:10.1080/ 16501970310012400

van Leeuwen PB, van der Net J, Helders PJM, Takken T (2004) Inspanningsparameters bij gezonde Nederlandse kinderen (Exercise parameters in healty Dutch children). Tijdschrift voor sportgeneeskundesport- en, bewegingswetenschappen 37:126132

Verschuren O, Takken T, Ketelaar M, Gorter JW, Helders PJ (2006) Reliability and validity of data for 2 newly developed shuttle run tests in children with cerebral palsy. Phys Ther 86:1107-1117

Waters RL, Mulroy S (1999) The energy expenditure of normal and pathologic gait. Gait Posture 9:207-231. doi:10.1016/S09666362(99)00009-0

Widman LM, McDonald CM, Abresch RT (2006) Effectiveness of an upper extremity exercise device integrated with computer gaming for aerobic training in adolescents with spinal cord dysfunction. J Spinal Cord Med 29:363-370

Widman LM, Abresch RT, Styne DM, McDonald CM (2007) Aerobic fitness and upper extremity strength in patients aged 11 to 21 years with spinal cord dysfunction as compared to ideal weight and overweight controls. J Spinal Cord Med 30(Suppl 1):S88S96 